\title{
The First Year After Colorectal Surgery in the Elderly
}

\author{
Verena N.N. Kornmann, Jeroen L.A. van Vugt, Anke B. Smits, Bert van Ramshorst, Djamila Boerma \\ Department of Surgery, St. Antonius Hospital, Nieuwegein, The Netherlands
}

Purpose: Surgery for colorectal malignancy is increasingly being performed in the elderly. Little is known about the impact of complications on late mortality. This study aimed to analyze whether a complicated postoperative course affects the 1-year survival in elderly patients.

Methods: All consecutive patients older than 75 years of age who underwent colorectal cancer surgery between January 2009 and April 2013 were included in this study. The main outcome was mortality at 1 year after surgery. Logistic regression analyses were performed to determine risk factors for a poor outcome (mortality) after survival of the early postoperative course of surgery at 1-year follow-up. Patients who died within 30 days postoperatively were excluded from analysis. Results: The early mortality rate was $6.3 \%(\mathrm{n}=15)$, and 2 patients died during follow-up as a result of complications after a second surgery. A total of 223 patients survived the perioperative period and were included in this study. Twenty-two patients $(9.9 \%)$ died during the first year of follow-up. Stage IV disease $(\mathrm{P}=0.002)$, complications of primary surgery $(\mathrm{P}=$ $0.016)$, and comorbidity $(\mathrm{P}=0.050)$ were risk factors for 1 -year mortality. Intensive care unit stay, reoperation and readmission were not associated with a worse 1-year outcome.

Conclusion: Elderly patients with stage IV disease at the time of surgery, comorbidity, and postoperative complications are at risk for mortality during the first year after surgery. A patient-tailored approach with special attention to perioperative care should be considered in the elderly.

\section{Keywords: Colorectal cancer; Colorectal surgery; Complications; Elderly; Survival}

\section{INTRODUCTION}

With aging of the population, colorectal surgery for cancer in older patients is increasingly being performed [1]. The surgical treatment of elderly patients with colorectal malignancies is challenging [2]. Two systematic reviews report lower overall survival rates compared with younger patients $[3,4]$. Understandably, the highest mortality rate in the elderly occurs during the early postoperative period $[5,6]$, but cancer-related survival is equal in older and younger patients when patients survive the first year after colorectal surgery [5, 7]. However, little is known about the survival and the readmission rates during the first year after sur-

Received: September 3, 2016 - Accepted: January 20, 2017

Correspondence to: Verena N. N. Kornmann. M.D.

Department of Surgery, St. Antonius Hospital, Koekoekslaan 1, 3435 CM

Nieuwegein, The Netherlands

Tel: +31-30-6092052, Fax: +31-30-6036578, E-mail: vnnkornmann@gmail.nl

(C) 2017 The Korean Society of Coloproctology

This is an open-access article distributed under the terms of the Creative Commons Attribution NonCommercial License (http://creativecommons.org/licenses/by-nc/4.0) which permits unrestricted non-

commercial use, distribution, and reproduction in any medium, provided the original work is properly cited. gery and about whether the outpatient course is determined by the early postoperative in-hospital course. The aim of this study was to evaluate the course of recovery immediately after the postoperative period and to investigate the influence of this early postoperative course on the outcome after 1 year. This knowledge may allow a patient-tailored approach and shared decision-making during hospital admission if complications of surgery occur.

\section{METHODS}

Patients aged 75 years or older who had undergone colorectal cancer surgery at the St Antonius Hospital, Nieuwegein, The Netherlands, between January 2009 and April 2013 were enrolled in a retrospective database. Data on the postoperative course, including postoperative complications (i.e., surgical and nonsurgical complications within 30 days after surgery, during admission, or during readmission within 30 days), early mortality (mortality within 30 days postoperatively or in-hospital), mortality during follow-up (within 1 year following surgery), reoperations, intensive care unit (ICU) stay, and readmissions, were evaluated. Comorbidity was categorized using the American Society of Anes- 
thesiologists physical status (ASA PS) classification and the Charlson Comorbidity Index [8, 9]. The Common Terminology Criteria for Adverse Events were used to define postoperative complications [10], and the Clavien-Dindo classification of surgical complications was used to classify the severity of complications [11-13].

Data are presented as number of patients with percentage or as median with interquartile range (IQR). Patients who died during the first 30 days after surgery or in-hospital (early mortality) were excluded from the analysis to determine only the variables contributing to a worse 1-year outcome in 'survivors of the surgery'. Differences between groups were tested with the chi-square test (for binomial outcomes). A logistic regression analysis (enter method) was used to determine independent risk factors for 1-year mortality in survivors of surgery, including all variables with a P-value inferior to 0.05 in the univariate analysis. A P-value $\leq 0.05$ (2-tailed) was considered significant. Data were analysed using IBM SPSS Statistics ver. 21.0 (IBM Co., Armonk, NY, USA).

\section{RESULTS}

A total of 256 patients were included. Of these patients, follow-up was incomplete in 16 patients (6.3\%). These patients were excluded from analysis. The early mortality rate was $6.3 \%(n=15)$ as a results of surgical $(n=5)$ and nonsurgical $(n=10)$ postoperative complications. A total of 225 survived the early postoperative period after colorectal surgery. Two patients died during followup due to complications after a second surgical procedure (1 stoma reversal and 1 adhesiolysis with partial small bowel resection for ileus). The remaining 223 patients were included in the analysis: 113 male (50.7\%) and 110 female patients (49.3\%) with a median age of 79 years (IQR, 76-83 years). Baseline and postoperative characteristics are summarized in Table 1.

During the first year after surgery, 22 of the 223 included patients $(9.9 \%)$ died due to progressive cardiopulmonary morbidity ( $\mathrm{n}=8$ ), secondary (lung) cancer $(\mathrm{n}=1)$, and progression of cancer with distant (organ) metastases or progression of clinical deterioration as a result of the cancer $(n=13)$. After 1 year, 201 of the 223 patients $(90.1 \%)$ were still alive.

Postoperative complications after initial colorectal surgery occurred in 103 patients (46.2\%) and were mostly graded as Clavien-Dindo grades I-II (Table 1). Thirty-eight patients needed reoperation due to complications (Clavien-Dindo grades III-IV). The occurrence of postoperative complications was associated with death during the first year of follow-up. Of patients with postoperative complications, $68.2 \%(\mathrm{n}=15)$ died after discharge during the first year versus $31.8 \%$ of the patients who died and had not suffered from complications $(\mathrm{n}=7)(\mathrm{P}=0.041)$. The grade of the complications (Clavien-Dindo grade $\geq \mathrm{III}$ ) did not influence the risk of death after discharge nor did the need for reoperation $(\mathrm{P}=0.498$ and $\mathrm{P}=0.457$, respectively) (Table 2 ).

A total of 13 patients (5.8\%) were admitted to the ICU for less
Table 1. Baseline and perioperative characteristics of the patients ( $\geq 75$ years, $\mathrm{n}=223$ )

\begin{tabular}{|c|c|}
\hline Characteristic & Value \\
\hline Age (yr) & 79 (76-83) \\
\hline Female sex & $110(49.3)$ \\
\hline Body mass index $\left(\mathrm{kg} / \mathrm{m}^{2}\right)$ & $25.1(23.0-27.5)$ \\
\hline Charlson Comorbidity Index & $3(2-4)$ \\
\hline ASA PS classification & $2(2-3)$ \\
\hline \multicolumn{2}{|l|}{ Surgical procedure } \\
\hline Right-sided colectomy & $93(41.7)$ \\
\hline Left-sided colectomy & 75 (33.6) \\
\hline Rectal resection & $51(22.9)$ \\
\hline (Sub)total colectomy & $4(1.8)$ \\
\hline Emergency surgery & $29(13.0)$ \\
\hline \multicolumn{2}{|l|}{ Approach } \\
\hline Laparotomy & $105(47.1)$ \\
\hline Laparoscopic & $104(46.6)$ \\
\hline Converted & $14(6.3)$ \\
\hline \multicolumn{2}{|l|}{ Stomy/anastomosis } \\
\hline Anastomosis & $137(61.4)$ \\
\hline No stomy & 130 (58.3) \\
\hline Diverting stomy & $7(3.1)$ \\
\hline Duration of surgery (min) & $100(75-135)$ \\
\hline Blood loss (mL) & $50(25-100)$ \\
\hline \multicolumn{2}{|l|}{ pTNM classification } \\
\hline pT & $2(2-3)$ \\
\hline $\mathrm{pN}$ & $0(0-1)$ \\
\hline Stage IV $(n=195)$ & $29(13.0)$ \\
\hline Length of stay in the hospital (day) & $7(5-12)$ \\
\hline \multicolumn{2}{|l|}{ Stay in ICU } \\
\hline 24-Hour observation & $16(7.2)$ \\
\hline Length of stay in ICU $<5$ days & $13(5.8)$ \\
\hline Length of stay in ICU $\geq 5$ days & $10(4.5)$ \\
\hline Readmission to the hospital & $30(13.5)$ \\
\hline Complications & 103 (46.2) \\
\hline Clavien-Dindo grades I-II & $64(28.7)$ \\
\hline Clavien-Dindo grades III-IV & $39(17.5)$ \\
\hline Reoperation/reintervention & $38(17.0)$ \\
\hline
\end{tabular}

Values are presented as median (interquartile range) or number (\%). ASA PS, American Society of Anesthesiologists physical status; ICU, intensive care unit.

than five days as a result of postoperative complications, and 10 patients (4.5\%) required more than five days of ICU care (Table 2). However, ICU stay (short or long) was not associated with mor- 
Table 2. Univariate logistic regression analysis $(n=223)$

\begin{tabular}{|c|c|c|}
\hline Variable & OR $(95 \% \mathrm{Cl})$ & P-value \\
\hline \multicolumn{3}{|l|}{ Patient characteristics } \\
\hline Age (yr) & $1.074(0.969-1.119)$ & 0.174 \\
\hline Male sex & $2.252(0.881-5.759)$ & 0.090 \\
\hline Body mass index $\left(\mathrm{kg} / \mathrm{m}^{2}\right)$ & $0.909(0.796-1.039)$ & 0.163 \\
\hline Charlson Comorbidity Index & $1.331(1.062-1.669)$ & 0.013 \\
\hline ASA PS classification & $2.782(1.320-5.863)$ & 0.007 \\
\hline \multicolumn{3}{|l|}{ Intraoperative characteristics } \\
\hline \multicolumn{3}{|l|}{ Surgical procedure } \\
\hline Right-sided colectomy & 1.000 (reference) & 0.729 \\
\hline Left-sided colectomy & $1.132(0.435-2.947)$ & 0.800 \\
\hline Rectal resection & $0.519(0.136-1.978)$ & 0.366 \\
\hline (Sub)total colectomy & $0.000(0.000-0.001)$ & 0.999 \\
\hline Emergency surgery & $1.564(0.490-4.998)$ & 0.450 \\
\hline \multicolumn{3}{|l|}{ Approach } \\
\hline Laparotomy & 1.000 (reference) & 0.344 \\
\hline Laparoscopic & $0.511(0.195-1.337)$ & 0.171 \\
\hline Converted & $1.179(0.237-5.875)$ & 0.840 \\
\hline \multicolumn{3}{|l|}{ Stomy/anastomosis } \\
\hline Anastomosis & $0.730(0.301-1.770)$ & 0.486 \\
\hline No stomy & $1.451(0.601-3.505)$ & 0.408 \\
\hline Duration of surgery (min) & $0.994(0.982-1.006)$ & 0.327 \\
\hline Blood loss (mL) & 0.999 (0.996-1.002) & 0.728 \\
\hline \multicolumn{3}{|l|}{ Pathology } \\
\hline Stage IV (versus stage $\leq 3$ ) & $5.448(1.932-15.357)$ & 0.001 \\
\hline \multicolumn{3}{|l|}{ Postoperative characteristics } \\
\hline Length of stay in the hospital (day) & $1.041(1.004-1.079)$ & 0.031 \\
\hline Length of stay in ICU $\geq 5$ days & $1.016(0.123-8.417)$ & 0.988 \\
\hline Readmission to the hospital & $2.071(0.702-6.107)$ & 0.187 \\
\hline Complications & $2.752(1.075-7.040)$ & 0.035 \\
\hline Clavien-Dindo grades I-॥ & 2.269 (0.927-5.553) & 0.073 \\
\hline Clavien-Dindo grades III-IV & 1.445 (0.499-4.183) & 0.498 \\
\hline Reoperation/reintervention & $1.497(0.516-4.342)$ & 0.457 \\
\hline
\end{tabular}

OR, odds ratio; $\mathrm{Cl}$, confidence interval; ASA PS, American Society of Anesthesiologists physical status; ICU, intensive care unit.

tality during follow-up $(\mathrm{P}=0.988)$. Thirty patients $(13.5 \%)$ were readmitted to the hospital within 30 days following surgery. After readmission, $83.3 \%$ of the patients survived the first year. Readmission was not associated with worse 1 -year survival $(P=0.187)$ (Table 2).

All survivors of primary surgery were added to the logistic regression analysis with the outcome being mortality at 1 year. In the univariate analysis, ASA PS classification, Charlson Comorbidity Index, stage IV disease, length of stay in the hospital, and
Table 3. Multivariable logistic regression of factors associated with 1-year mortality

\begin{tabular}{lcc}
\hline Variable & \multicolumn{1}{c}{ OR $(95 \% \mathrm{Cl})$} & P-value \\
\hline ASA PS classification & $2.453(1.002-6.008)$ & 0.050 \\
Stage IV disease, yes & $5.716(1.82-17.642)$ & 0.002 \\
Complication, yes & $4.112(1.308-12.930)$ & 0.016 \\
\hline
\end{tabular}

$\mathrm{OR}$, odds ratio; $\mathrm{Cl}$, confidence interval.

postoperative complications were associated with mortality at 1 year (Table 2). ICU stays of more than 5 days, reoperations, and readmissions were not associated with 1-year mortality. Variables added to the multivariate analysis were ASA PS classification, stage IV disease, and postoperative complications; Charlson Comorbidity Index and length of stay in the hospital were excluded from the analysis because of their high correlations with the other variables. For patients who survived the primary surgery, all three included parameters were independently associated with mortality at 1 year with odds ratios (ORs) of 5.716 (95\% confidence interval $[\mathrm{CI}], 1.82-17.642)(\mathrm{P}=0.002)$ for stage IV disease, 4.112 (95\% CI, 1.308-12.930) $(\mathrm{P}=0.016)$ for postoperative complications, and $2.453(95 \% \mathrm{CI}, 1.002-6.008)(\mathrm{P}=0.050)$ for ASA PS classification (Table 3 ).

\section{DISCUSSION}

This is the first study to demonstrate that $10 \%$ of the elderly patients who undergo colorectal cancer surgery are likely to die within 1 year after discharge. Tumor stage, postoperative complications, and ASA PS classification were associated with worse 1 -year outcome in survivors of the early postoperative period. Patients who died during the early postoperative period all had complications of high degree, but for those who survived this early period, the 1-year survivals were equal for patients with high and those with low degrees of complications.

The length of ICU stay was not associated with a worse outcome at 1 year. This indicates that if a patient survives a prolonged ICU stay, the prognosis for the next year is comparable to that for other patients who had not had such an experience. However, no information about quality of life (QoL) after (prolonged) ICU stay is known. A study by Montuclard et al. [14] concluded that prolonged ICU stay ( $>30$ days) in elderly patients ( $\geq 70$ years old) was associated with an acceptable QoL, but emerging evidence suggests that (prolonged) ICU stay is associated with a decreased quality of life known as the postintensive care syndrome [15-17].

Dekker et al. [5] demonstrated slightly higher 1-year mortality rates of $20.1 \%-23.2 \%$ in elderly ( $\geq 75$ years) colorectal cancer patients. Factors that were significantly associated with an impaired 1 -year outcome in their study were male sex (in rectal cancer surgery), increased age, and tumor grade (in both colon and rectal cancer surgery). When patients survived the first year after surgery, survival was comparable for both older and younger patients 
for both colon and rectal cancer surgery [5]. In a study among patients of 70 years or older who underwent noncardiac surgery, postoperative pulmonary and renal complications also proved to be independently associated with a decreased long-term survival (hazard ratios of 2.41 and $6.07(\mathrm{P}<0.001)$, respectively) [18].

A study demonstrated that elderly patients were more likely to be readmitted to the hospital compared with younger patients [19]. Furthermore, readmission was found to be strongly associated with a higher 1-year mortality rate (adjusted OR, 2.44; 95\% CI, 2.25-2.65) [20]. The reasons for readmission were comparable with those in our study, but readmission was not associated with a worse 1-year outcome in our study, which only included elderly (unadjusted OR, 2.07; 95\% CI, 0.70-6.11) $(\mathrm{P}=0.187)$.

The surgical treatment of colorectal malignancies in the aging population remains a formidable challenge, and the chances of a successful outcome with a good quality of life over the remaining life span need to be weighed against the risk of potential complications with a detrimental outcome. Present-day informed-consent procedures and shared decision-making with patients and relatives require an optimal knowledge of the factors influencing the outcome of surgical procedures. The management of the older patient requires a stepwise approach at different stages. In the preoperative stage, an optimal risk assessment is necessary either to decide to exclude the patient from surgery based on morbidity profiles or to define the level of needed care tailored to the patient's clinical and physical status. An individualized rehabilitation program should guarantee an optimization of the preoperative nutritional and cardiopulmonary status. In the perioperative stage, state-of-the-art surgical and anesthesiological techniques are obligatory, and every effort should be put into the prevention, early detection, and containment of perioperative complications. Early identification of patients at risk for an adverse perioperative course is of paramount importance. In patients with a considerable comorbidity, a multidisciplinary approach may be opted for to optimize the preoperative condition and to prevent (comorbidity-related) postoperative complications. A patient-tailored approach with special attention to perioperative care is essential in the elderly.

In this study, we demonstrated that once the patient survives colorectal surgery, albeit after reoperation or prolonged ICU care, survival during the first year after discharge is comparable to that of other patients without such experiences. We also demonstrated that the occurrence of complications (which are mainly cardiopulmonary) after surgery is a predictor of increased risk of death. Thus, an elderly patient suffering from postoperative complications after colorectal surgery should be the focus of special attention in order to provide the best chance for survival.

\section{CONFLICT OF INTEREST}

No potential conflict of interest relevant to this article was reported.

\section{REFERENCES}

1. Etzioni DA, Beart RW Jr, Madoff RD, Ault GT. Impact of the aging population on the demand for colorectal procedures. Dis Colon Rectum 2009;52:583-90.

2. Chang GJ, Skibber JM, Feig BW, Rodriguez-Bigas M. Are we undertreating rectal cancer in the elderly? An epidemiologic study. Ann Surg 2007;246:215-21.

3. Surgery for colorectal cancer in elderly patients: a systematic review. Colorectal Cancer Collaborative Group. Lancet 2000;356: 968-74.

4. Manceau G, Karoui M, Werner A, Mortensen NJ, Hannoun L. Comparative outcomes of rectal cancer surgery between elderly and non-elderly patients: a systematic review. Lancet Oncol 2012;13:e525-36.

5. Dekker JW, van den Broek CB, Bastiaannet E, van de Geest LG, Tollenaar RA, Liefers GJ. Importance of the first postoperative year in the prognosis of elderly colorectal cancer patients. Ann Surg Oncol 2011;18:1533-9.

6. Ihedioha U, Gravante G, Lloyd G, Sangal S, Sorge R, Singh B, et al. Curative colorectal resections in patients aged 80 years and older: clinical characteristics, morbidity, mortality and risk factors. Int J Colorectal Dis 2013;28:941-7.

7. Al-Refaie WB, Parsons HM, Habermann EB, Kwaan M, Spencer MP, Henderson WG, et al. Operative outcomes beyond 30-day mortality: colorectal cancer surgery in oldest old. Ann Surg 2011; 253:947-52.

8. Charlson ME, Pompei P, Ales KL, MacKenzie CR. A new method of classifying prognostic comorbidity in longitudinal studies: development and validation. J Chronic Dis 1987;40:373-83.

9. Sundararajan V, Henderson T, Perry C, Muggivan A, Quan H, Ghali WA. New ICD-10 version of the Charlson comorbidity index predicted in-hospital mortality. J Clin Epidemiol 2004;57: 1288-94.

10. Cancer Therapy Evaluation Program of the National Cancer Institute. Common terminology criteria for adverse events (CTCAE) version 4.03, June 14, 2010. Bethesda (MD): National Cancer Institute; 2010.

11. Clavien PA, Sanabria JR, Strasberg SM. Proposed classification of complications of surgery with examples of utility in cholecystectomy. Surgery 1992;111:518-26.

12. Dindo D, Demartines N, Clavien PA. Classification of surgical complications: a new proposal with evaluation in a cohort of 6336 patients and results of a survey. Ann Surg 2004;240:205-13.

13. Clavien PA, Barkun J, de Oliveira ML, Vauthey JN, Dindo D, Schulick RD, et al. The Clavien-Dindo classification of surgical complications: five-year experience. Ann Surg 2009;250:187-96.

14. Montuclard L, Garrouste-Orgeas M, Timsit JF, Misset B, De Jonghe B, Carlet J. Outcome, functional autonomy, and quality of life of elderly patients with a long-term intensive care unit stay. Crit Care Med 2000;28:3389-95.

15. Needham DM, Davidson J, Cohen H, Hopkins RO, Weinert C, 
Wunsch $\mathrm{H}$, et al. Improving long-term outcomes after discharge from intensive care unit: report from a stakeholders' conference. Crit Care Med 2012;40:502-9.

16. Desai SV, Law TJ, Needham DM. Long-term complications of critical care. Crit Care Med 2011;39:371-9.

17. Cuthbertson BH, Roughton S, Jenkinson D, Maclennan G, Vale L. Quality of life in the five years after intensive care: a cohort study. Crit Care 2010;14:R6.

18. Manku K, Bacchetti P, Leung JM. Prognostic significance of post- operative in-hospital complications in elderly patients. I. Longterm survival. Anesth Analg 2003;96:583-9.

19. Kunitake H, Zingmond DS, Ryoo J, Ko CY. Caring for octogenarian and nonagenarian patients with colorectal cancer: what should our standards and expectations be? Dis Colon Rectum 2010;53:735-43.

20. Greenblatt DY, Weber SM, O'Connor ES, LoConte NK, Liou JI, Smith MA. Readmission after colectomy for cancer predicts oneyear mortality. Ann Surg 2010;251:659-69. 